canal of the horse, Mr. Krabbe examined, during the last four years, the bodies of one hundred horses which were brought for anatomical purposes to the Veterinary College at Copenhagen, between the months of September and April in each session. In these horses he found Tenia perfoliata, 28 times; $T$. mamil. lana, 8 times; Ascaris megalocephala, 16 times; Strongylus armatus, 86 times; S. tetrucanthus, 78 times (in 67 horses out of 86); and Oxyuris curvula, twice. Of $T$. perfoliata the number found was mostly less than 25 ; sometimes it was over, and twice between 100 and 200 were found, while once no less than 400 were met with. In general they were lodged in the cæcum. T. mamillana of Mehlis, a species overlooked by Dujardin and most French writers on the subject, was described and figured by Gurlt in 1831 ; generally less than 25 , but sometimes up to 72, were met with, mostly in the anterior part of the small intestines ( $T$. plicata, R., was never met with). The Ascaris never occurred in larger numbers than I1. S. armatus was never met with in the small intestine; in the crecum it was common ; much less so in the first portion of the colon, where very fine specimens of a dark bluish red colour were found; generally the number met with was below 25 , but once nearly 200 were found. Of 1,409 samples, 1,029 were females and 380 males. $S$. tetracanthus was found in the cæcum and throughout the colon. The literature of this subject would appear to be very scanty, and the author hopes that the attention of veterinary surgeons in other parts of the world may be attracted to this subject. Ample opportunities of following it up exist in British India, America, and the Cape of Good Hope district.

The Domestication of DeER.-A very interesting correspondence is published in the American Naturalist for June between Mr. Brown, the superintendent of the Philadelphia Zoological Gardens, and Mr. J. D. Caton. It relates chiefly to the question of the domestication of species of deer. Of the twelve species kept in the Philadelphia Gardens the mule deer (Cervus macrotis) have bred during 1878 and 1879; of five fawns one died when two days old; the other four, though most carefully nursed and fed with astringent food, as well as supplied with iron water and gentian powders, \&c., all died of a diarrhcea caused by malignant disease. Five specimens of moose-deer and eight of caribou died at periods varying from three months to two years and five months in the moose and not beyond nine months in the caribou from hypertrophy of the heart. The pronghorn ( $A$. americana) all died speedily from diarrhœea or hypertrophy of the heart ; change of food and tonics seemed to have no effect upon them. Of ten or twelve individuals none lived more than fifteen months. The wapiti and common deer (C. virginianus), however, have done well, and several fawns were raised of $C$. campestris, $C$. aristolelis, and C. dama. Of $C$. leucurus the Gardens possessed but a single specimen. In the case of the mule deer Mr. Brown is disposed to account for the mortality by the difficulty of supplying them with a sufficient amount of their proper (arboreal) food, which has to be replaced by dry food and grass. Mr. Caton, writing from Ottawa, Illinois, states that he had lost the last of his stock of mule deer and also of C.columbianus, and that he is satisfied that they cannot be successfully domesticated in his grounds. IIe concludes that they get at something which does not agree with them; indeed all his experimen's with ruminants, fera nature whose natural habitat is confined to the United States west of the Missouri River, have proved failures. Mr. Caton has succeeded well in hybridising the Virginian deer with the Ceylon deer and the Acapulco deer. The hybrids seem to be perfectly healthy and prolific, several of the hybrids from the Virginian deer and Acapulco buck having borne perfectly healthy twin fawns. On some $c f$ the hybrids the metatarsal gland is wanting, and on some it is present, while some have it on one hind leg and not on the other.

The Findler Crabs, - Mr. J. S. Kingsley, in a further contribution to the Proceedings of the Academy of Natural Sciences of Philadelphia, revises the genus Gelasimus, and as a result he makes a great reduction in the number of species. This has been done, not with any desire to overturn the work of others, but as the result of a study of the forms known all over the world. The range of many species is greatly extended. He refers the genus to the family Macrophthalmidæ of Dana; and it is characterised by its rhomboidal carapace, broad in front, elongated eye-stalks, and a great inequality of the chelipeds or nipping feet of the male. The latter is the most constant character of value. The species fall into two groups according as the front between the eyes is very narrow or wide; and the latter have males with a five-jointed or seven-jointed abdomen.

Organs of DeEp-Sea Antmals.-During his researches on the fauna of the Caspian Sea, M. O. Grimm has studied the modifications which are undergone by the organs of sense in animals which inhabit great depths. Among them several have well-developed organs of sight, which seems to prove that even at very great depths light is not completely absorbed. Such are the Caspian Mysis, the Gammaracanthus caspizs, several Breckia, and others, but on the contrary, there are at the same depths many species whose eyes are quite atrophied, and in these species we observe that other organs of sense receive a greater development. Such is the case in Niphargus and Onesimus. But, whilst Niphargus caspizes bears well-developed organs of smell and of touch on its antennæ, in Onesimus, which, as well as the former, has but rudimentary eyes, only organs of touch are to be found on its jaws. M. Grimm explains this last difference by the circumstance that the former species usually remains in water, whilst On:simus likes to remain in the mud at the bottom, where it searches for its food very much like a mole.

\section{CHEMTCAL NOTES}

In the fournal of the American Chemical Society, vol. ii., $\mathrm{Mr}, \mathrm{P}$. Collier describes a new mineral from the Champlain iron region, which resembles thorite in its physical properties, but differs therefrom in containing a relatively large quantity of uranium. Analysis showed $9^{\circ} 96$ per cent. of uranic oxide, and $5^{\circ}$ o7 per cent. of thoric oxide, with $19^{\circ} 3^{8}$ per cent. of silica, the remainder consisting of oxides of lead, aluminium, iron, calcium, magnesium, and sodium, with moisture and combined water.

Mr. Collier gives an account, in the same journal, of expcriments he has made, which seem to point to a new possible source of crystallisable sugar. He finds that the juice of various varieties of fully ripe sorghums contains from 13 to 15 per cent. of sucrose, with 1 or 2 per cent. of glucose.

SPECIAL attention has been recently given to the liquids included in the microscopical pores of certain minerals, and it has been shown by Zimmler that these pores contain not only water, but also sometimes carbonic acid. Prof. Karpinsky publishes now in the Memoirs of the St. Petersburg Society of Naturalists the results of his experiments on the liquid contained in the pores of the Uralian amethyst. The mineral having been broken in a tube filled with mercury, the fluid immediately evaporated, and being brought in contact with a solution of oxide of barium, proved to be carbonic acid ( $\mathrm{r}^{\circ} \mathrm{O}$ cubic millimetres at $30^{\circ}$ ). The pressure under which the carbonic acid was liquefied may be estimated as seventy-three atmospheres, which would correspond to a pressure of a column of water 2,336 feet high.

AT the meeting of the French Academy of May 17, 24, and 3I, notes were read by MM. Ditte and Berthelot, on the cold produced by the action of acids on hydrated salts, e.g., hydrochloric acid on bydrated sodium sulphate. The action is regarded as complex : an exothermal chemical reaction occurs in accordance with Berthelot's "law of maximum work," but unless the products of this action are totally insoluble, secondary changes take place; these changes are chiefly conditioned by the amount of heat evolved in the primary action. In the special cases in question the heat disengaged in the chemical change is less than the heat absorbed in the liquefaction of the water of crystallisation which separates from the hydrated salt, hence the sum of the heat changes is negntive.

THE densities of chlorine, bromine, and jodine at high temperatures cannot yet be regarded as determined. Victor Meyer, in a recent paper in the Berliner Berichte, admits the justice of Crafts' criticism of his determinations of temperature (see Nature, vol, xxi, p. 56r, letter by Dr. Armstrong); his latest results give for iodine at about $\mathrm{I}, 050^{\circ}$, a density equal to $\mathbf{S}_{3} \mathbf{I}_{2}$, and at an extremely high temperature (exact numbers not ye given), a density of 4.55 , which nearly corresponds with that calculated on the supposition that at this temperature the iodine molecules are entirely dissociated into atoms (calculated number $=4 * 39)$. Meyer and Crafts, working by Dumas' method, and using an iodine thermometer, find the density at $1,468^{\circ}$ to be $5^{\circ} 05$ (calculated for $\frac{2}{3} I_{2}, 5.83$; for I, $4^{*} 39$ ). The density for free chlorine seems to be normal $\left(\mathrm{Cl}_{2}\right)$, even at extremely high temperatures ; but if the chlorine be produced in the vapour-density 
apparatus-by heating platinous chloride-the density at about $\mathbf{1}, 400^{\circ}$ agrees with that calculated for $\frac{2}{3} \mathrm{Cl}_{2}$. Bromine produced by heating platinic bromide in the apparatus gave a density equal to $\frac{2}{3} \mathrm{Br}_{2}$ at about $\mathbf{1}, 400^{\circ}$. Meyer and Crafts published numbers in Comptes Rendus, which gave for free bromine at about $1,400^{\circ}$, a density between that calculated for $\mathrm{Br}_{2}$ and that for $\frac{2}{3} \mathrm{Br}_{2}$, viz., $4^{\circ} 43\left(\mathrm{Br}_{2}=5^{\prime} 52, \frac{2}{3} \mathrm{Br}_{2}=3^{\circ} 64\right)$. Meyer's vapourdensity method is somewhat adversely criticised in the last number of the Berliner Berichte by Pettersson and Ekstrand, who give numbers which they regard as proving that the method does not give good results at high temperatures when the substance under examination is a solid. Solids, they say, condense on their surfaces considerable quantities of air, and when the solid is thrown into the highly-heated apparatus this air is evolved, is measured with the air representing the volume of the gasified substance, and so vitiates the result. It is certainly worthy of note that both Crafts and Meyer obtained a normal density for chlorinethe only halogen element gaseous before being brought into the apparatus-at the highest temperature at which they experimented. Pettersson and Ekstrand regard Dumas' method as the only altogether satisfactory one; they describe a modification of this process. It is to be remarked that the density of mercury vapour-which chemists generally regard as consisting of atoms -is shown by Meyer's results to be remarkably constant through a large range of temperature.

Alexr. Naumann has arranged Meyer and Crafts' results on the density of iodine vapour in a table (in the Berichte for June r4) showing the percentage dissociation of iodine molecules at various temperatures; the results are in keeping with the deduction made by Naumann from the kinetic theory of gases, viz., that equal temperature-intervals currespond to a regularly increasing amount of dissociation up to 50 per cent. but after this to a decreasing amount of dissociation. Naumann regards this agreement between the theoretically-deduced, and the actual results as affording evidence in favour of the correctness of Meyer and Crafts' measurements of high temperatures. This subject is likely to receive a considerable amount of attention, as it has an all-important bearing on the question of the elementary nature of the so-called elements. Deville and Troost, in a recent number of Compt. Rend., estimate the boiling-point of zinc as $940^{\circ}$, which is $100^{\circ}$ lower than the number generally accepted on the evidence of older determinations by the same authors.

Chemico-Physical investigation has lately led to some im. portant results. Schneider, in a recent number of the Berliner Berichte, has shown that any solution of malic acid containing more than $34^{\circ} 24$ percent. of the acid rotates the polarised ray to the right, whilst a solution containing less than this amount is lævarotatory. Solutions of sodium malate are dextrorotatory when of greater strength than $47^{\circ} 43$ per cent., but lævarotatory when containing less than this quantity of the salt.

Some little time since Brihl published-also in the Berichtean important paper on the connection between the refraction equivalents and the chemical structure of carbon compounds; he showed that if the refraction equivalents are calculated for a number of carbon compounds, by the help of Cauchy's formula, for a ray of infinite wave-length, a distinct connection can be seen to exist between the numbers thus obtained and the number of "doubly-linked" carbon atoms in the compound. A further communication by the same author appears in a recent number of the same journal. The refraction equivalent of a carbon compound is equal to the sum of the atomic refractions of its constituent elements; the value of the atomic refraction of carbon varies according to the "linking" of the carbon atomfor every pair of doubly-linked carbon atoms present in a compound, the refraction equivalent of the compound is greater by 2 than that i calculated by the use of the number expressing the ordinary atomic refraction of carbon. The atomic refraction of oxygen when doubly linked to carbon is $3^{*} 29$, when in the group $\mathrm{OH}$, or when linked to two atoms, it is $2^{*} 7 \mathrm{r}$. The atomic refraction of the halogen elements is constant. Brïhl concludes that the atomic refraction of a monovalent element is independent of the atom-linking of its compounds, but that this statement does not hold good for polyvalent elements.

IN connection with this work of Brühl, the recent experiments of Prof. Janovsky (Wien. Akad. Anz., June 3) are of interest. According to Janovsky the linking of carbon atoms is of subordinate influence in determining the refraction equivalents of carbon compounds, for isomers with similar linking have unequal refractive indiceș. In homologous series a similar differ- ence of refractive indices corresponds to an equal difference o groups only where the series belong to similarly saturated hydrocarbons (alike in position). The refractive power of unsaturated hydrocarbons is greater than that of saturated. Lastly, the author shows that the determination of refraction-coefficients of solid bodies from their solutions is unreliable, as the refractive power depends on the state of aggregation.

In the Annales Chim. Phys. Long shows that a connection exists between the velocities of diffusion and other physical constants, and the composition of various salts ; thus the values of the velocity of diffusion, molecular volumes, and electric conductivity, are in the same order for the chlorides, bromides, and iodides of the alkali metals.

ST EDEL publishes in the Berichte the first part of an investigation on the vapour-tensions of substituted halogen derivatives of ethane; his researches, which are not however yet completed, seem to show that the increase of vapour-tension for $\mathbf{I}^{\circ}$ (between $400 \mathrm{~mm}$. and $\mathrm{r}, 060 \mathrm{~mm}$.) is equal for a bromo-derivative and that chloro-derivative which contains, in place of one bromine atom, two chlorine atoms linked to one carbon atom: e.g. $\mathrm{CH}_{3}-\mathrm{CH}_{2} \mathrm{Br}$ and $\mathrm{CH}_{3}-\mathrm{CHCl}_{2}: \mathrm{CH}_{2} \mathrm{Cl}-\mathrm{CH}_{2} \mathrm{Br}$ and $\mathrm{CH}_{3}-\mathrm{CCl}_{3}$, \&c.

J. VARENNE continues in Compt. rend. his researches on the passivity of iron, which have been already noticed in NATURE. He finds that if a piece of iron be immersed in nitric acid of sp. gr. $\mathrm{I}^{\prime} 325$, oxides of nitrogen are evolved for a few moments; the escape of gas, however, suddenly ceases; after a time it begins again at one point of the metallic surface, spreads over the entire surface, again ceases, once more recommences, and so on intermittently, If an iron tube be very partially immersed in strong nitric acid, and after passivity is established, the passive part be placed in weaker acid for a time, it is found that by then slowly immersing the tube further in the acid the whole becomes passive, but that this passivity is very easily destroyed, e.g., by shaking the tube. The passivity is less the more dilute the weaker acid, the rougher the metallic surface, and the greater the diameter of the iron tube.

IN the Berliner Berichte experiments are detailed by Reinitzer and Goldschmidt, whereby these chemists have succeeded in preparing the compound $\mathrm{P}_{4} \mathrm{O}$, about the existence of which there has been much difference of opinion, $\mathrm{P}_{4} \mathrm{O}$ is a reddishcoloured amorphous substance produced by the action of phosphorus, or of zinc, on $\mathrm{POCl}_{3}$.

Hoppe-Seyler publishes in the Zeitschrift f. physiol. Chem. a continuation of his work on chlorophyllan, a crystalline substance closely resembling chlorophyll, obtained from green grass. By treatment with alcoholic potash, chlorophyllan yields, amongst other products, an acid characterised by giving a splendid purple-coloured ethereal solution, which exhibits very marked rose-red fluorescence. For this compound $-\mathrm{C}_{20} \mathrm{H}_{34} \mathrm{O}_{3}-\mathrm{Hoppe}$ Seyler proposes the name of dichromatic acid. The absorption spectrum of the acid in ethereal solution is marked by two bands between $C$ and $D$, whilst the spectrum of the fluorescent light from the same solution exhibits two bright bands in exactly the same positions.

ACCORDING to Adolf Mayer's experiments described in the Berliner Berichte, oxygen has no direct influence on fermentation. The addition of potassium-hydrogen tartrate to a strong syrup containing yeast causes the yeast cells to grow rapidly, and fermentation to proceed with ease.

THE meeting of the French Academy of Sciences, held on July 5 , presented some interesting incidents which are not likely to appear in the Comptes rendus. A very interesting discussion took place between M. Wurtz and MM. Dumas and St. Claire Deville on the occasion of the presentation of a memoir on the density of vapour of iodine by M. Troost. M. Dumas and M. St. ClaireDeville asserted that it was impossible to accept the idea of a dissociation of vaporised iodine a.t a high temperature, as no permanent alteration resulted from this alleged change in the composition of this substance. M. St. Claire Deville said he was;opposed to all theories of molecules and atoms, as science had only to deal with facts, and not with mere assumptions or speculations. It might be supposed that the coefficient of expansion of iodine increased rapidly with increase of temperature. M. Wurtz argued that the diminution of the density was too consider. able to be accounted for otherwise than by a dedoublement of molecules, All the speakers agreed that these phenomena, which are very curious, should be carefully investigated with 
increased attention and care, M. Wurtz having resumed his seat, M. Dumas presented a letter from Mr. Crookes, in which he summarises his theories of radiant matter, and submits them for discussion before the French Academy. After having explained the Crookesian view of the fourth statc of matter, M. Dumas added that he felt confident these assumptions would be the occasion of discussions of the same character as that which the Acarlemy had just witnessed.

\section{PHYSICAL NOTES}

HERR DORN of Breslau has published a fresh series of experiments on the propagation of electricity by current water in tubes,

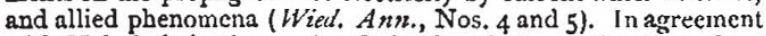
with Helmholtz's theory, he finds the electromotive force from current water in capillary tubes independent of the cross section and the length of these. The value of the "electric moment" of water and glass ( $3{ }^{\circ} 936$ Daniell) deduced from this electromotive force corresponds nearly to that deduced by IIelmholtz from Quincke's observations on the propayation of water in glass tubes by the electric current. Observations of the electric current produced by water flowing in capillary tubes lead to a somewhat smaller value. For wider tubes (within pretty wide limits) the current strength, with a given mean velocity of the strearning water, proves empirically to be nearly proportional to the radius of the tube. Traces of a sliding of the water on the glass-wall may perhaps co-operate in producing the variations of electromotive force observed in course of time. Through motion of material particles in a liquid, therefore, an electric current arises.

THE diffusion of salts in aqueous solution has been investigated by Herr Long (Wiid. Ann., No. 4), by a method similar in principle to that of Schulnmeister (though different in detail), viz., making a continuous water-current flow over the salt solution and meacuring the amount of diffusion by the quantities of salt that pass over in given times. Various interesting relations were found, e.g., the chlorides, bromides, and iodides of the alkali metals form a series, in which $\mathrm{NH}_{4}$ stands between $\mathrm{K}$ (the high(r) and $\mathrm{Na}$; and $\mathrm{KCl}, \mathrm{KBr}, \mathrm{KI}$, and $\mathrm{KCy}$ have nearly the same velocity of diffusion. Such is the case also with the corresponding $\mathrm{NII}_{4}$ and $\mathrm{Na}$ salts and with the chlorides of the bi. valent metals $\mathrm{Ba}, \mathrm{Sr}, \mathrm{Ca}$, and $\mathrm{Mg}$, the nitrates, and the sulphates. It seems generally that those salts which diffuse most quickly also conduct best in aqueous solution. Salts with large molecular weight and volume seem to diffusc most easily, while among the waterless salts those which absorb most heat in dissolving or (the same thing) whose molecules, through the work donc, finally reach the finest state of division, have the greatest velocity of diffusion. The chlorides of the alkalies stand in the same series with regard to molecular volumes, velocities of diffusion, conductivity, and absorption of beat. This is the case, too, with the corresponding bromides and iodides. Cyanide of potassium behaves as to diffusion and conductivity exactly likc the chloride, bromidic, and iodide of the metal. In the second group (nitrates) the order is the same as to conductivity and diffusion ; but with regard to molecular volumes and heat-absorption the salts form a special scric.s. In the group of sulphates the individual salts have the samc order as to diffusion and con ductivity, but the values for molecular volume and heat of solu. tion are quite irregular; indecd as regards velocity of diffusion and absorption of heat the waterless saits seem to staud in inverse order. These results are fully discussed by Herr long.

A CURIOU!s physical phenomenon has been lately described by Dr. Grassi (Reale Ist. Lomb. R'end., f. viii. and ix.). An apparatus is formed of three concentric vessels with an annular space of about two centimetres between the first and the second, and the second and the third. The outer space is filled with oil, the next with water. The oil is heated by a gas furnace to a little over $100^{\circ}$, and the water boils. Then hot oil, at e.g., $150^{\circ}$ is joured into the central space. This quickly couls to a temperature close on $100^{\circ}$. Dr. Grassi found that the central oil cooled more rapidly the higher the temperature of the outer oil; and with more delicate apparatus (in which the vaporised water was conducted and returned, and the outer oil kept at any required constan temperature) he arrived at definite numerical results, which he tabulates. With the outer oil at a mean temperature of $129^{\circ} \%$, c.g., the time of cooling of the inner oil from $130^{\circ}$ to $110^{\circ}$ wa 49s. ; when the former was $105^{\circ} \cdot \mathrm{r}$, the latter was $57 \mathrm{~s}$. Alcohol and ether gave more decided results. The maximum difference was got with ether; the outer oil being at $57.5^{\circ}$, the inner took
$25 \mathrm{~s}$. to cool from $57^{\circ}$ to $50^{\circ}$ ( 7 degrees); whereas the former being $39^{\circ} 3^{\circ}$, the latter became $39^{\circ} 5 \%$. In all the experiments the cooling of the inner oil commenced at a temperature littlc above the maximum of the external oil. When the outer oil is at a higher temperature, at a certain point the heat begins to prevail which is transmittel directly from the outer to the inner oil. An analogous phenomenon (to which Dr. Grassi refers) was that of some members of the Accademia del Cimento, who found that water in a vessel surrounded by ice cools more rapidly if the ice be heated to accelerate fusion.

1)R. I. PULUJ lately communicated a paper to the Scientific Club of Vienna on "Radiant Electrode-matter," in which he traverses the researches of Crookes, Hittorf, Goldstein, and others upon the phenomena of electric discharges in high vacua. IIe maintains at the outset that the discharges of "radiant matter" observed by Crookes at the negative pole are not residual gas at all, but are particles of metal torn off from the surface of the pole. IIe thinks this proved by the mirror-like dejosits of metal that are formed on objects interposed in the path of the discharge. That aluminium in this way forms no mirror is a difficulty in the way of this theory; but I)r. Puluj gets over this by remarking that the cause of this lics in the chemical constitution of the metal, and that the particles of an aluminium clectrode fly round so far that they deposit themselves on the clectrocle! All the magnetic effects of these discharges Dr. Puluj regards as explainable by ordinary electro-magnetic laws, assuming that a stream of electrificd matter acts as an electric current ; but he apparently is not acquainted with the theory put forward by Maxwell on this point. Dr. Puluj has also constructed what he calls an electrode-lamp, which gives a bright light when worked by an induction-coil capable of affording a spark of ro $\mathrm{cm}$. length. In this lamp the radiant discharges of electrodematter are concentrated upon a piece of carbon which glows with a white heat, but remains unchanged and unconsumed.

I) . Cusco, ophthalmic surgeon in one of the hospitals of r'aris, has invented a lens of variable focus, in which the pressure of a column of water or other transparent liquid is made to alter the curvature of the flat faces of a cylindrical cell of hrass closed with thin glass disks. The pressure can be regulated by a manometer gauge to any required degrce within the limits of working. It is said that the lens gives a sharp, well-defined focus. It is constructed for Dr. Cusco by M. I.aurent.

M. HeNRI BeCQUEREL continues his researches on the mag. neto-optic properties of gases. He has recently examined the gases oxygen, nitrogen, carbonic dioxide, nitrous oxide, and olefiant gas, and finds that, except in the case of oxygen, the magnetic rotation of the plane of polarisation due to a field of given intensity varies inversely as the rquare of the wave-length of the ray, as is the case with solids and liquids. In an older rescarch of Becquerel's it was shown that for non-magnetic solids and liquids the rotation $R$ was proportional to a function of the refractive index $n$, very nearly represented by the expression $n^{2}\left(n^{2}-1\right)$; or, in other words, the quantity $\frac{R}{n^{2}\left(n^{2}-1\right)}=c$. For all non-magnetic solids and liquids the value of $c$ lay between 0.26 and $0^{\circ} 59$. In the case of gases in which the rotation is but a ten-thousandth part of that of most 3olids or liquids the same result holds gond, and the values of $c$ for gases fall hetween 0.26 and 0.59 . The above law, that the magnetic rotation is inversely proportional to the square of the wave-length, implies that violet rays are uore rotated than the red; or, in other words, that there is a positive dispersion. In the case of oxygen it is found that the red rays are rotated more than the green, affording an inverse or negatize dispersion. This is the more curious as oxygen gives a positive rotation as if it were a diamagnetic body. In fact, Hecqucrel renarks, oxygen behaves as if it were a mixture of a magnetic and a diamagnetic body, the magnetic having small neyative rutation and great negative disprersion, the diamagnetic having great positive rolation and small positive dispersion.

\section{GEOGRAPHICAL NOTES}

IN a private letter addressed to Ilerr von IIesse-Wartegg, the well-known explorer, Dr. Nachtigall, writes from Berlin :- "The Gicrman African Society (Deutsche Afrikanische Gesellschaft) has at the present moment not less than six different expeditions travelling through Central Africa. The large funds necessary for the outfitting of these numerous travellers are raised partly 